\title{
The effects of cancer treatment during pregnancy on foetal and child development
}

\section{Tineke Vandenbroucke, MSc}

KU Leuven - University of Leuven, Department of Oncology; University Hospitals Leuven, Department of Obstetrics and Gynecology, Leuven, Belgium

Address: Herestraat 49, 3000 Leuven, Belgium

\section{Magali Verheecke, MD}

KU Leuven - University of Leuven, Department of Oncology; University Hospitals Leuven, Department of Obstetrics and Gynecology, Leuven, Belgium

Address: Herestraat 49, 3000 Leuven, Belgium

\section{Monica Fumagalli, MD}

Fondazione IRCCS Ca' Granda Ospedale Maggiore Policlinico Milano, Neonatal Intensive Care Unit; Università degli Studi di Milano, Milan, Italy

Address: Via Francesco Sforza, 35, 20122 Milano, Italy

\section{Christianne Lok, PhD}

Department of Gynecologic Oncology, Center Gynecologic Oncology Amsterdam, Amsterdam, The Netherlands

Address: Plesmanlaan 121, 1066 CX Amsterdam, The Netherlands

\section{Frédéric Amant, PhD}

KU Leuven - University of Leuven, Department of Oncology; University Hospitals Leuven, Department of Obstetrics and Gynecology, Leuven, Belgium

Netherlands Cancer Institute, Center Gynecologic Oncology Amsterdam, Antoni van Leeuwenhoek, the Netherlands

University of Amsterdam, Center Gynecologic Oncology Amsterdam, Academic Medical Center, the Netherlands

Address: Plesmanlaan 121, 1066 CX Amsterdam, The Netherlands

\section{Corresponding author:}

Prof. Dr. Frédéric Amant

Center Gynecologic Oncology Amsterdam

Netherlands Cancer Institute

Plesmanlaan 121, 1066 CX Amsterdam

The Netherlands

E-mail: f.amant@nki.nl

Phone number : 0031205122983 


\title{
POSTPRINT VERSION
}

\begin{abstract}
Lately, it has become clear that for specific cancers under well-defined circumstances oncological treatment in pregnancy is possible. In this article, we summarize the available literature on foetal, neonatal, short- and long-term impact of prenatal exposure to cancer treatment on the child. So far, outcomes of children are generally reassuring, but long-term follow-up is limited. The most important risks of chemotherapy during pregnancy are preterm birth and small for gestational age babies. Chemotherapy in the first trimester is contraindicated due to an increased risk of congenital malformations. Studies on outcomes of children exposed to radiotherapy, targeted or hormonal therapy in pregnancy are scarce. Careful registration of women undergoing cancer treatment in pregnancy and examination of their children is indispensable. Well documented mental and physical status of children exposed to cancer treatment in utero will allow physicians and parents to decide best whether or not to treat cancer during pregnancy.
\end{abstract}

\section{Introduction}

The most frequent occurring malignancies in pregnancy are breast cancer, cervical cancer, haematological malignancies and melanoma. The prevalence and detection of cancer in pregnancy has increased because many women postpone their pregnancies until a later age and because of the availability of diagnostic modalities that can safely be used in pregnancy. Cohort studies reported an incidence of cancer in pregnancy of 112 (per 100,000 women) in 1994 and of 191 (per 100,000 women) in 2008.1,2 Until recently, fear for foetal toxicity generally withheld physicians to start oncological treatment during pregnancy. Termination of pregnancy, delay of maternal treatment or induction of preterm labour often occurred.

Well documented mental and physical status of children exposed to cancer treatment in utero will allow physicians and parents to decide best whether or not to treat cancer during pregnancy. In this article, we summarize the available evidence on the effects of antenatal cancer treatment, including surgery, radiotherapy and systemic therapy on intrauterine life, the neonate, and child development until adulthood.

\section{Cancer treatment during pregnancy}

Cancer treatment has three main modalities: surgery, radiotherapy and systemic therapy. After appropriate diagnosis and staging, oncologic treatment is possible during an ongoing pregnancy under well-defined circumstances, without jeopardizing foetal safety. In the following section, we will discuss the possibility of surgery, radiotherapy and systemic therapy, including chemotherapy, targeted therapy and hormonal therapy, in pregnancy.

\section{Surgery in pregnancy}




\section{POSTPRINT VERSION}

In many cancer types, surgery is an essential part of oncologic treatment. Surgery in pregnancy is feasible when certain precautions are taken. Data on safety of surgery are available from the frequent surgical procedures in pregnancy for non-obstetrical and non-oncological reasons. ${ }^{3,4}$ Most important obstetrical risks of surgery in pregnancy are miscarriage, premature delivery or foetal distress (decreased placental perfusion and foetal hypoxia). ${ }^{5}$

Surgery-related risks of maternal hypotension, hypoxia, or stress, pose a greater risk to the foetus than anaesthetic agents. ${ }^{6}$ Therefore, maternal monitoring is crucial to prevent hypoxia, hypotension and hypoglycaemia and the best guarantee for foetal wellbeing. ${ }^{7}$

Every procedure after 20 weeks gestational age should be performed in the "left lateral tilt" position to avoid compression of the vena cava and maintaining the cardiac preload. Abdominal surgery is preferably planned in the second trimester because the risk of miscarriage is decreased and the size of the uterus still allows a certain degree of access. Specific risks of laparoscopy in pregnancy are hypercapnia, perforation of enlarged uterus and reduced blood flow due to increased abdominal pressure and use of carbon dioxide. However, laparoscopic surgery can be performed in pregnant patients without increased risk to the mother or foetus by an experienced surgeon and taking into account published guidelines. ${ }^{8}$

Continuous foeto-uterine monitoring by cardiotocogram during surgery is possible during nonabdominal surgery, but should only be used when the foetus is viable..$^{9}$ Tocolytic agents are only indicated when manipulation of the pregnant uterus is unavoidable.

\section{Radiotherapy}

The biological effects of radiotherapy are incompatible with pregnancy because of the radiosensitivity of the rapidly growing embryo and foetus. However, its effects depend on gestational age and dosage. These effects can be deterministic or stochastic (Table 1). The dominant deterministic effect of preimplantation irradiation is early death of the conceptus. ${ }^{10}$ In the first trimester of pregnancy during organogenesis, irradiation above the threshold of an absorbed dose of 0.1 Gy increases the risk of malformations. ${ }^{11}$ The central nervous system continues to develop after the major organogenesis and can be impaired by exposure to irradiation during a longer period. The neuronal plasticity and natural redundancy can compensate up to a certain level for irradiation damage. Experimental animal studies and human data from atomic bomb studies show a high sensitivity of the central nervous system until 15 weeks gestation. ${ }^{12}$ Irradiation of an older foetus may lead to growth restriction and functional organ defects.

One stochastic effect is the increased risk of all types of childhood cancers, but especially leukaemia (3-4 per 1000 children compared to the background risk of 2-3 per 1000 children). ${ }^{10}$ This increase in risk is independent of the gestational age at the moment of exposure. Because of these uncertainties, radiotherapy is often postponed until the postpartum period. However, if delay is detrimental for the mother, radiotherapy of upper body parts with foetal shielding is possible, especially in the first or second trimester, when the distance between the foetus and the field of irradiation is at largest, reducing the 


\section{POSTPRINT VERSION}

foetal exposure (Figure 1). ${ }^{13}$ Because of the relation between effects on the foetus and distance from the target lesion, a phantom system and a physicist who calculates the estimated foetal dosage are indispensable. ${ }^{10}$ When the foetal exposure is below the threshold dose of $100 \mathrm{mGy}$, radiotherapy can be considered. ${ }^{10}$ Radiotherapy of the pelvis is not compatible with an ongoing pregnancy. ${ }^{10}$

\section{Systemic therapy}

Physiologic changes also influence pharmacokinetics with respect to distribution, metabolism and excretion of systemic therapy, possibly leading to reduced drug exposure and efficacy. Many drugs can cross the placenta depending on their size, lipophilia, protein binding, ionization and the presence in the placenta of protein drug transporters. ${ }^{14,15}$ However, animal studies showed that the concentrations of drugs in the foetal plasma are lower compared to the maternal plasma confirming the protecting role of the placenta. ${ }^{14,15}$ The extend of this placental protection differs per chemotherapeutic agent, with high passage of platin-based therapy ( $57 \%$ for carboplatin) and low passage of taxanes ( $1.4 \%$ for paclitaxel and not detectable for docetaxel) and anthracyclines (4.0\% for epirubicin, $7.5 \%$ for doxorubicin). ${ }^{14,15}$ Chemotherapy is cytotoxic and interferes with cell growth. Therefore, the timing of chemotherapy as well as the number of cycles and dose administered are crucial factors contributing to foetal outcome. With limited knowledge on safety of chemotherapy administration during the first trimester (i.e. period of organogenesis), it remains experimental and contraindicated. From second trimester on, evidence is available that some chemotherapeutic agents can be administered without an increased risk on foetal malformations and without major neonatal and short-term problems. ${ }^{16}$ Nonetheless, also since the central nervous system starts to develop in the fifth week of pregnancy and its development continues throughout pregnancy and even after birth, the potential impact of chemotherapy administration needs to be well considered. A baseline pelvic ultrasound before chemotherapy administration is therefore recommended to detect pre-existing anomalies. Other reported potential risks of in utero exposure to chemotherapy during the second and third trimester of pregnancy are low birth weight, subtle changes to the heart function and premature delivery. ${ }^{17-21}$

Targeted therapy is now an important therapeutic option and its use is increasing steadily. ${ }^{22}$ Data on the safety of these agents in pregnancy is overall lacking. Based on their small size, different structure, metabolism and pharmacokinetics, they are potentially teratogenic and harmful for the foetus. ${ }^{23}$ Most is known on trastuzumab, which is an antibody directed against the HER-2-protein, used in the treatment of breast cancer. Trastuzumab is associated with oligohydramion when administered in the second or third trimester. The reason for this is the blockage of the epidermal growth factor (EGFR)-2 in the foetal kidney with subsequent inhibition of kidney cell proliferation. ${ }^{24}$

Knowledge on hormonal therapy effect on pregnancy especially originates from women receiving adjuvant therapy for breast cancer. Although the majority of children born after exposure to tamoxifen are healthy, tamoxifen is sometimes associated with foetal abnormalities. The four case reports of congenital anomalies that are published describe ambiguous genitalia, craniofacial malformations, Goldenhar syndrome and Pierre-Robin sequence, however the prevalence of congenital malformations that can be attributed to tamoxifen is unknown. ${ }^{25-28}$ Therefore, tamoxifen is discouraged in pregnancy. 


\section{POSTPRINT VERSION}

\section{Effects of systemic cancer treatment during pregnancy on the foetus}

The main foetal, neonatal and long-term risks of systemic cancer treatment during pregnancy, as reported in literature, are summarized in Figure 2. In Table 1 of the appendix, the most important and largest studies on the foetal, neonatal and long-term outcome of children after prenatal exposure to cancer treatment published between 2000 and 2017 are shown.

In the following section, we will discuss the possible impact of systemic therapy on the development of congenital malformations and growth restriction. As stated before, during the first trimester, the foetus is extremely vulnerable, and chemotherapy given in this period induces an elevated risk of congenital malformations, ranging from 7.5 to $25 \%$, compared to $4.1 \%$ in general population. ${ }^{29-32}$ In contrast, Aviles et al. reported no congenital malformations in 54 children born after chemotherapy exposure during the first trimester. ${ }^{33}$ Although they concluded the 'safety' of chemotherapy given during the first trimester, information that allows estimating the teratogenic risks (the developmental stage at exposure, the dose, the duration, and the frequency of drug administration) is lacking. ${ }^{34}$ If chemotherapy is administered beyond this critical period, there is no increased risk of congenital malformations (about 3 $\%$ major malformations, $7.5 \%$ minor). ${ }^{17}$

Contradictory results have been published on the impact of chemotherapy on the foetal growth. While some studies recorded normal birth weight and length according to gestational age, most studies revealed a higher incidence of Small-for-Gestational-Age (SGA) children after chemotherapy exposure. 17,18,21,35-37 SGA is defined as a birth weight below the 10th percentile of gender- and agematched controls and refers to the failure of the foetus to achieve its growth potential. Incidences between 7 and $17 \%$ of SGA were recorded by Cardonick and lacobucci, depending on type of cancer and treatment. ${ }^{21}$ Several years later, the same group found a significant difference in birth weight at delivery in 231 women diagnosed with cancer after chemotherapy and no chemotherapy exposure. ${ }^{38} \mathrm{In}$ the study of Amant et al., 25\% (24/95) of children prenatally exposed to chemotherapy were born SGA. ${ }^{16}$ Growth restricted foetuses exhibit a significant risk of perinatal morbidity and mortality. Preterm birth, neonatal hypothermia, hypoglycaemia, morbidities and even perinatal mortality can occur in the acute setting, more cardiovascular and metabolic diseases are seen in the long-term follow-up of these children. ${ }^{39,40}$ Growth restriction can be caused by foetal, maternal, or placental causes. Direct (direct toxicity of the chemotherapeutic agents to the trophoblasts), indirect effects (inflammation) or the maternal illness itself (malnutrition, anaemia) with high stress levels might contribute to the increased frequency of SGA seen in pregnancies complicated by cancer. ${ }^{41,42}$ Recently, Lu et al. reported a positive association between diagnosis of cancer during pregnancy and the risk of stillbirth, mainly SGA stillbirths, and with preterm SGA births. However, this association declined over the study period (19732012), suggesting an improvement in obstetric and oncologic care. ${ }^{43}$ Fortunately, although SGA birth seems to be more frequent after cancer during pregnancy, and especially chemotherapy during pregnancy, postnatal growth seems to be unaffected. A study that followed growth curves until 3 years of age showed that most SGA born children caught up their growth curves within the follow-up period. ${ }^{16}$ 


\section{POSTPRINT VERSION}

\section{Neonatal outcome after prenatal exposure to chemotherapy}

In the next section, we will give an overview of the possible impact of chemotherapeutic agents during pregnancy on the risk of preterm delivery and neonatal morbidities.

In the cohort study by Amant et al., $61.2 \%$ of children prenatally exposed to cancer treatment were born preterm (gestational age $<37$ weeks), in contrast with a general population percentage of preterm births of $6 \cdot 8-8 \%$ in the participating countries. ${ }^{16}$ Although the neurodevelopment of these babies was normal at a median age of 22 months, there was a negative impact of prematurity on the cognitive outcome (similar effect in the study and control group).

Prematurity, and in particular late preterm birth $\left(34^{+0}\right.$ to $36^{+6}$ weeks gestation), is indeed the most commonly reported neonatal outcome: a mean gestational age at birth of $35.8 \pm 2.8$ weeks was reported by Cardonick et al. on 157 chemotherapy-exposed neonates born to mothers enrolled in the USA International Cancer and Pregnancy Registry between 1995 and 2008. ${ }^{38}$ Similar findings were described in the majority of published studies and case series on infants born to pregnant mothers with cancer. ${ }^{17,18,37,44-46}$

Prematurity represents the main determinant of early neonatal morbidities and later neurodevelopmental impairment: the more immature the infant, the higher the risk of postnatal complications and impaired long-term outcome. Late preterm infants are the most represented premature infants but an increased risk of adverse early neonatal outcomes (temperature instability, respiratory distress syndrome, excessive weight loss and dehydration, sepsis, hypoglycaemia, jaundice and neuromorbidities) has been well demonstrated also in this low-risk preterm population. ${ }^{47}$

In case of pregnancy complicated by cancer, preterm birth is mainly due to iatrogenic preterm delivery based on the need to initiate maternal treatment or due to deterioration of maternal health status.

Recently, Lu et al. reported about the risk of stillbirth and infant mortality associated with maternal cancer during pregnancy based on nationwide health registers in Sweden. ${ }^{43}$ Both neonatal mortality and preterm birth were positively associated with maternal cancer diagnosed during pregnancy and the association with preterm birth was due to iatrogenic instead of spontaneous preterm birth. Moreover, $89 \%$ of the association of maternal caner during pregnancy with neonatal morbidity was explained by preterm birth. In the study of Van Calsteren et al., $51 \cdot 2 \%$ of 172 children born after cancer diagnosed during pregnancy were admitted to a neonatal intensive care unit and prematurity was the main indication for admission ( $85 \cdot 2 \%$ of cases). ${ }^{17}$

The incidence of preterm labour in the general population is $4 \%$. In comparison, Van Calsteren et al. observed an incidence of preterm labour of $12.9 \% .{ }^{17} \mathrm{~A}$ high rate of spontaneous preterm birth or preterm premature rupture of membranes $(30 \%)$ was observed in ten women treated with dose-dense chemotherapy (every two weeks). With conventional chemotherapy this event was not more likely to occur $(17 \%, N=99) .{ }^{46}$ Chemotherapeutic agents may cause an increase of preterm contractions, but up till now, no clear evidence on the underlying pathophysiology is known. ${ }^{17}$ Therefore, close monitoring, including gynaecologic examination and cervicometry, is advised.

Maternal haematological malignancies carry the highest risk of obstetric and perinatal complications, such as premature birth and intrauterine growth restriction. Impairments in nutrient exchange, blood 


\section{POSTPRINT VERSION}

flow, and oxygen delivery in the intervillous placental spaces due to leukaemia cells have been suggested as potential pathogenetic mechanisms. ${ }^{17}$

Most of the short term neonatal morbidities reported in babies born to pregnant mothers with cancer are likely to be related to the premature birth, in particular respiratory distress syndrome. ${ }^{45,48}$ In the observational study by Loibl et al. on treatment of breast cancer during pregnancy, adverse neonatal events (sepsis, jaundice, SGA, hypercalciuria, necrotising enterocolitis, patent foramen ovale, cerebral bleeding, respiratory distress syndrome, malformations, pulmonary artery stenosis, aspiration pneumoniae, increased muscle tension, high serum concentration of $\mathrm{N}$-terminal pro B-type natriuretic peptide (proBNP), neutropenia, anaemia) appeared to be more common in neonates in utero exposed to chemotherapy (15\%) compared to those not exposed (4\%) and in preterm compared to term infants, but differences were not clinically significant. ${ }^{36} \mathrm{~A}$ tendency, towards a higher incidence of high-grade respiratory distress syndrome was documented by Fischer et al. in a retrospective analysis on 19 preterm and three term infants born to mothers with oncologic diseases, compared to controls born to healthy mothers and matched for gestational age..$^{44}$

Transient haematotoxicity is a potentially serious neonatal side effect of antenatal chemotherapy but this is a rare event when a 3-week interval is maintained between the mother's last course of chemotherapy and delivery. Few cases of leukopenia/pancytopenia, requiring haematological growth factors, have been reported when an unplanned delivery occurred within a few days after chemotherapy administration (leukopenia and pancytopenia in two babies born ten weeks after administration of a multiple agents regimen for acute lymphatic leukaemia; neutropenia in one child born just 19 days after treatment with docetaxel and anaemia requiring transfusion in one child exposed to cyclophosphamide, doxorubicin, vincristine and prednisone five days before spontaneous preterm delivery). ${ }^{17,38}$ However, anaemia was reported by Chang et al. as the most common side effect of treatment of acute myeloid leukaemia during pregnancy and Fischer et al. described a case of pancytopenia (treated with substitution of packed red cells, platelets and erythropoietin) in a child whose mother suffered from the same malignancy. ${ }^{44,49}$

\section{Long-term outcome of children after prenatal exposure to chemotherapy}

In the following section, we will discuss the possible long-term impact of prenatal exposure to cancer treatment, and especially chemotherapy, on general health, cardiotoxicity, ototoxicity, dental problems, neurocognitive development, school performance and behaviour problems of the children.

\section{General health}

Several studies have documented general health status of children born to mothers treated for cancer during pregnancy. Some of them only used parent-report questionnaires ${ }^{19,48}$, while others also performed a clinical examination ${ }^{16,18,33,35,50}$ and only few included a control group ${ }^{16,20}$. After in utero exposure to chemotherapy and/or radiotherapy, no major health problems were reported and the incidence of medical problems was in general comparable between study and control group or to the general population. However, Murthy et al. reported an increased incidence of allergies and/or eczema 


\section{POSTPRINT VERSION}

$(18 / 50,36 \%)$ in the study group at a median age of 7 years, as compared to $11-22 \%$ in the general population. ${ }^{19}$ In the study of Amant et al., the differences in incidence of allergies and skin disorders were not statistically significant at a median age of 22 months (respectively $14 / 119,11.8 \%$ allergies in the study group versus $7 / 109,6 \cdot 5 \%$ in the control group and $13 / 119,10 \cdot 9 \%$ skin disorders in the study group versus $16 / 109,14.8 \%$ in the control group). ${ }^{16}$

\section{Cardiotoxicity}

Anthracyclines, as being important agents in the treatment of breast cancer and haematological malignancies, are frequently administered during pregnancy. Nonetheless these agents are cardiotoxic, in the acute as well as chronic setting. ${ }^{51}$ Acute cardiotoxicity may occur within the first two weeks after treatment, is usually reversible and is characterized by an acute and mild depression of the contractile function. Chronic cardiotoxicity can occur within the first year (early onset) or many years after chemotherapy treatment (late onset) and can lead to ventricular dysfunction, heart failure, cardiomyopathy and death. Anthracyclines are widely used in the treatment of childhood leukemia, with a four-fold increase of cardiovascular death. ${ }^{52}$ However, cardiotoxicity seems to manifest itself after longer intervals and has a different pattern of development compared to adults (restrictive versus dilated cardiomyopathy). ${ }^{53}$ Adverse cardiac foetal outcomes have been described after exposure to anthracyclines in utero, despite low transplacental passage. ${ }^{14,18,54}$ Because of the different properties of the foetal myocardium as compared to the adult myocardium (single nucleus, fewer sarcomeres per mass unit, immature sarcoplasmic reticulum, lower number of mitochondria, underdeveloped antioxidant pathways), the foetal heart may be more vulnerable to anthracyclines. ${ }^{55,56}$ Aviles et al. reported the first study on the cardiac outcome after prenatal exposure to anthracyclines with normal echocardiographic findings for all children. ${ }^{57}$ In the acute phase, there is no significant effect of maternal anthracycline exposure on both the maternal and foetal cardiac functions. ${ }^{58}$ In 2012. Amant et al. evaluated the global heart function of 65 children prenatally exposed to chemotherapy and compared the results to controls. Statistically significant small differences in the ejection fraction, fractional shortening, and some of the diastolic parameters (isovolumic relaxation time and mitral A-duration) were noticed, but there were no clinically relevant differences. ${ }^{18}$ Comparable results were found in a subgroup analysis on 50 children exposed to anthracyclines compared to healthy controls. Also in 2015, subtle between-group differences in tissue Doppler imaging measurements of the basal segment of the interventricular septum were recorded between 47 children exposed to chemotherapy and their nonexposed matched controls. ${ }^{16}$ However these differences were not present in the 26 children exposed to anthracyclines. These small differences as well as the knowledge that anthracycline cardiotoxicity may only become apparent after many years indicate that long-term follow-up is warranted.

\section{Ototoxicity}

Studies on children and adults with cancer treated with cisplatin have found an increased incidence of ototoxicity, especially hearing loss. ${ }^{59,60}$ Adverse effects on hearing have also been reported after prenatal exposure to cisplatin. Amant et al. reported results of 21 children prenatally exposed to chemotherapy, aged 5.0 to 17.6 years, who were assessed by means of an audiometry. ${ }^{18}$ Eighteen 


\section{POSTPRINT VERSION}

children (85.7\%) had normal outcome, including three children exposed to cisplatin in utero. One child, who was exposed to cisplatin during pregnancy, was diagnosed with hearing loss in the high regions at the age of 6 years. However, computed tomography showed a perforated eardrum, which may be a consequence of multiple middle ear infections. Minor right-side hearing loss in the low regions was found in a twin exposed to idarubicin and cytosine arabinoside in utero, diagnosed at 6 and 9 years of age. Pre-existing neurodevelopmental problems may confound the results in this twin. A single case report of a boy with severe bilateral perceptive hearing loss after prenatal exposure to cisplatin ( 5 cycles of $70 \mathrm{mg} / \mathrm{m}^{2}$ ), diagnosed shortly after birth, was described by Geijteman et al. ${ }^{61}$ These adverse effects described may be a consequence of in utero exposure to chemotherapy. Nevertheless, it is hard to determine the direct effect of chemotherapy on hearing loss at older age, because of the existence of many confounding factors such as ear infections and exposure to loud noise. Given the observation that platin-based therapy may cross the placenta in substantial amounts (up to $57 \%$ for carboplatin) ${ }^{15}$ and the anecdotal hearing loss, cisplatin should only be administered after careful consideration. In many cases, carboplatin can replace cisplatin with the same oncologic efficacy, though with less toxicity and no neurotoxicity. ${ }^{9}$

\section{Dental problems}

Survivors of childhood cancer treated with chemotherapy may experience damage to the developing teeth and are more prone to dental caries. ${ }^{62}$ Since primary teeth start to develop around 11 to 14 weeks of gestation and tooth formation is completed postnatally, dental problems may be a possible adverse effect of second and/or third trimester exposure to chemotherapy. One study reported sound teeth in two children at age 18 months and three years after exposure to adriamycin and cytoxan in the third trimester of pregnancy. ${ }^{63}$ However, dental examinations have not yet been included in large cohort studies.

\section{Neurocognitive development and school performance}

Adults and children with cancer who are treated with chemotherapy often report cognitive problems, such as disturbances in intelligence, attention, memory, language, information processing, judgment and planning. ${ }^{64,65}$ This is referred to as "chemo-brain" in the literature. 66 These changes have also been found in imaging studies, such as a recent MRI study on a series of breast cancer survivors, showing an association between changes in cognitive functioning and changes in cerebral white matter integrity. $67,68 \mathrm{Up}$ to now, the pathophysiological basis for this relationship has not yet been found, but an excess of cytokines such as tumour necrosis factor $\alpha$ (TNF- $\alpha$ ) in the brain has been postulated as a possible mechanism, inducing oxidative stress and mitochondrial dysfunction, which may lead to impaired working memory. ${ }^{69}$

When chemotherapy is administered during pregnancy, there might be a long-term impact on neurocognitive functioning, as the development of the central nervous system starts around the fifth week of pregnancy and continues throughout pregnancy. Aviles and Neri were the first to report on the neurocognitive outcome of 84 children aged 6 to 29 years born to mothers treated with chemotherapy during pregnancy for haematological malignancies. ${ }^{35}$ Neurological and psychological evaluations were 


\section{POSTPRINT VERSION}

performed by a physician and schools were asked to provide information on educational performance. No abnormalities in learning were observed, children exhibited a normal educational performance and neurological examinations were normal. However, the methodology of this study is not well specified and no intelligence or other neuropsychological tests were performed. In 2012, the same group reported on the outcome of 54 children and adults, aged 3.8 to 32.0 years, exposed to chemotherapy in the first trimester of pregnancy. ${ }^{33}$ Verbal, performance and full-scale intelligence were within normal ranges as compared to a control group of children. Also, educational performance was normal, taking social and economic factors into account. A study by Hahn et al. reported on the outcome of 40 children, assessed between 2 months and 13 years, who were in utero exposed to fluorouracil-adriamycincyclophosphamide (FAC) chemotherapy for maternal breast cancer. ${ }^{48}$ Parent or guardian surveys were sent out. Two out of 18 children at school-age required special attention in school: one for attention deficit hyperactivity disorder and one for Down's syndrome. All other children were thought to develop normally. In 2012, Amant et al. published the first prospective multicentre evaluation of 70 children, aged 1.5 to 18 years (median 22 months), in utero exposed to chemotherapy. ${ }^{18}$ Mental development, intelligence, attention and memory tests were performed at predefined ages and compared to the norms of the respective tests. The results of all tests were considered normal. However, both children of a twin pregnancy were found to have a severe cognitive delay. Moreover, prematurity was related to a worse cognitive outcome. In 2015, the same group reported on results of 129 children, aged between 1.5 and 3.5 years, born to women who were diagnosed with cancer during pregnancy. ${ }^{16}$ Between them, 96 children were exposed to chemotherapy in utero (alone or in combination with other treatments), 11 children to radiotherapy (alone or in combination), 13 to surgery alone, 2 to other drug treatments and 14 to no treatment. The results were compared to a control group of children born after an uncomplicated pregnancy and delivery and 1:1 matched to the study children for test age and gestational age at birth. Cognitive development, assessed by means of the Bayley Scales of Infant and Toddler Development, was comparable between the cancer and control group. Subgroup analyses per treatment type also did not reveal significant differences compared to the control group. However, the negative prognostic effect of preterm birth on cognitive outcome was confirmed in both study and control children, indicating that prematurity may lead to a delay in cognitive development, independent of cancer treatment during pregnancy. Another study was recently published by Cardonick et al., comparing cognitive outcome and school performance of 35 chemotherapy-exposed children to 22 non-exposed children born to mothers diagnosed with cancer during pregnancy. ${ }^{20}$ Mental development, intelligence, and school performance were assessed between 1.5 and 10.4 years and were mostly within normal ranges. However, a score below the normal range was found for three children (one chemotherapy-exposed and two non-exposed children). The number of abnormal results was not significantly different between the study and control group. Also, school performances were comparable between the two groups (normal results for chemotherapy-exposed versus non-exposed children: $75 \%$ versus $67 \%$ for mathematics and $75 \%$ versus $83 \%$ for reading). As the median follow-up duration in most studies that have been published up to now is restricted to infancy, toddlerhood or early childhood and given the knowledge that neurocognitive problems may become more apparent at school-age, long-term follow-up studies 


\section{POSTPRINT VERSION}

including detailed assessment of neurocognitive functions such as intelligence, attention, memory and executive functions are highly needed.

\section{Behaviour problems}

Amant et al. reported on the behavioural outcome of 21 children aged 5.0 to 15.9 years and exposed to chemotherapy in utero, assessed by means of the Child Behaviour Checklist $(\mathrm{CBCL})^{70}$, a questionnaire on behaviour problems to be filled out by the parents. ${ }^{18}$ Twenty-nine percent of the children had an increased score for internalizing problems (e.g., symptoms of depression, anxiety, withdrawn behaviour), externalizing problems (e.g., rule-breaking, delinquent or aggressive behaviour) or the total problems scale (a combination of internalizing and externalizing problems together with social problems and thought problems). Cardonick et al. compared parent-reported behaviour problems, assessed by means of the $\mathrm{CBCL}$, between 35 chemotherapy-exposed children and 22 non-exposed controls, aged 1.5 to 10.4 years, all born to women who were diagnosed with cancer while pregnant. ${ }^{20}$ There were no significant between-group differences for internalizing, externalizing or total problem behaviour. However, $23 \%$ (8/35) of the chemotherapy-exposed group and 18\% (4/22) of the non-exposed controls demonstrated behaviour problems in the borderline or clinical range. The incidence of internalizing behaviour problems was significantly higher in older than in younger children. Behaviour problems were not significantly affected by maternal survival, mother's health status at the time of evaluation, child sex or age. When cancer is diagnosed during pregnancy, increased maternal stress hormone levels may cross the placenta and thereby increase foetal stress hormone levels, causing hypothalamic-pituitaryadrenal axis dysregulation, and thereby increasing the incidence of emotional and behaviour problems in childhood and adolescence. ${ }^{71}$

\section{Future perspectives}

Since the year 2000, most studies have focused on foetal and neonatal effects and on general health, cognitive and cardiac outcome of children after prenatal exposure to chemotherapy. However, most studies did not follow up child development until adulthood, and lacked controls. Therefore, the impact of in utero exposure to cancer treatment on fertility and the development of cancer remains largely unknown. The knowledge that anthracycline-based cardiotoxicity may develop over many years and that cognitive problems may become more apparent at school-age, underscores the importance of longterm follow-up. As the transplacental passage of chemotherapeutic drugs may vary in substantial amounts between different chemotherapeutic agents, one might hypothesize a differential effect on child development. However, different types of chemotherapeutic agents are often combined and currently mainly data on drugs used for breast cancer were included in follow-up studies. In addition, chemotherapy may be supplemented by diagnostic imaging, surgery, radiotherapy, supportive drugs and maternal stress. It is thus very challenging to disentangle the impact of single factors on child development. Studies documenting the outcome of children after in utero exposure to radiotherapy, targeted therapy or hormonal therapy are scarce. Large prospective cohort studies are needed to address the long-term effects of different types of maternal cancer treatment on child development until adulthood. Such a study is currently ongoing within the International Network on Cancer, Infertility and 


\section{POSTPRINT VERSION}

Pregnancy (INCIP, www.cancerinpregnancy.org). In Table 2, we present the largest ongoing studies on cancer during pregnancy.

\section{Conclusion}

It is counterintuitive to administer cancer drugs that are designed to kill rapidly dividing cells. The knowledge about neonatal and long-term safety data is an important indicator for patients and clinicians to consider cancer treatment during pregnancy. When this knowledge is not available, the likelihood for termination of pregnancy, delay of maternal treatment or induction of preterm delivery is high. In contrast, when the outcome data are available and discussed with the patient, the decision to continue the pregnancy and treat the maternal cancer is much more likely. The importance of data that describe the outcome of children after antenatal exposure to chemotherapy therefore should not be underestimated. Overall, the available evidence shows that antenatal exposure to chemotherapy in second and/or third trimester of pregnancy is not detrimental to foetal life. However, the most important risks are small for gestational age babies and preterm birth, which is associated with an increased risk of neurocognitive dysfunctioning. Moreover, hearing loss in the child has been reported after cisplatin administration during pregnancy. Chemotherapy administered during first trimester of pregnancy is associated with an increased risk of congenital malformations and is therefore contraindicated. Further research is necessary to delineate better the safety of each individual drug, their long-term safety on general health, cognitive development and cardiac functions, and the impact on dental problems, fertility and secondary cancers. To date, the benefits in favour of chemotherapy administration during second or third trimester of pregnancy are stronger than the disadvantages. Cancer treatment during pregnancy is a complex co-incidence. Best care is provided in referral centres in a multidisciplinary setting.

\section{Key messages}

1. Overall, the available evidence shows that antenatal exposure to chemotherapy in second or third trimester of pregnancy is not detrimental to foetal life. Chemotherapy administered during first trimester of pregnancy is associated with an increased risk of congenital malformations and is therefore contraindicated.

2. However, the most important risks are small for gestational age babies and preterm birth, which is associated with an increased risk of neurocognitive dysfunctioning. Therefore, antenatal chemotherapy in second or third trimester of pregnancy should be preferred above iatrogenic prematurity.

3. Surgery can be performed throughout all stages of pregnancy. Radiotherapy in pregnancy with adequate shielding can be considered when treatment cannot be postponed and if the estimated foetal dose of radiation is $<100 \mathrm{mGy}$, although outcomes of children are scarce in the literature. The effects of new targeted therapies are still unclear and should therefore not be advised in pregnancy. Hormonal treatment in pregnancy is contraindicated.

4. Further research is needed to delineate better the safety of each individual drug, their longterm safety, and the impact on neurocognitive functioning, cardiotoxicity, hearing loss, dental problems, fertility and secondary cancers. 


\section{POSTPRINT VERSION}

\section{Search strategy and selection criteria}

We searched PubMed for articles in English published from January 1, 1985 to April 30, 2017. Articles on the use of cancer treatment during pregnancy and on foetal, neonatal and long-term effects of cancer treatment during pregnancy were identified, using the following search terms: ("Pregnancy"[Mesh] OR "Pregnancy, High-Risk"[Mesh] OR "Pregnancy Outcome"[Mesh]) AND ("Infant, New-born"[Mesh] OR "Foetus"[Mesh] OR "Infant, Low Birth Weight"[Mesh] OR "Child Development" [Mesh]) AND "Neoplasms/therapy"[Mesh] AND "Antineoplastic Agents"[Mesh]). Additional papers were retrieved by adding "Prenatal Exposure Delayed Effects" [Mesh] or "Practice guidelines as topic" [Mesh] to "Pregnancy" AND "Neoplasm" AND "Antineoplastic Agents". Further relevant articles were found from reference lists of reviews or primary research articles. We mainly focused on articles published from 2000 on, since the research has clearly expanded from then, but we did not exclude commonly referenced older publications.

\section{Contributors}

All authors contributed to the conceptualization, literature search, and development and editing of the review.

\section{Declaration of interests}

There are no conflicts of interest.

\section{Acknowledgements}

FA is senior clinical investigator and MV and TV are research fellows of the Research FoundationFlanders (F.W.O.). This work is supported by a grant of the European Research Council (ERC) and the Dutch Koningin Wilhelmina Fonds (KWF). The authors are grateful to all parents and children who facilitated collection of scientific data that help us to guide future parents.

\section{Figure and illustration legends}

Figure 1. Consequences of foetal exposure to irradiation of the upper body parts

Red lines indicate the radiation beams for the example of brain, thyroid and breast cancer. Focused beams are represented by solid lines, scatter beams by dashed lines. The highest dose of radiation is focused on the tumour, but scatter beams with low radiation dose convert away from the tumour. Curved black lines indicate the abdominal shielding, as radiotherapy should always be performed with appropriate shielding. Double arrows indicate the distance from the radiation field to the pregnant fundus. The physicist calculates the estimated foetal exposure, depending on the tumour type, the dosage, the distance between the radiation field and the foetus, and the type of shielding. During first and second trimester, the distance to the radiation field may result in a low and safe foetal exposure. In third trimester, this distance is very narrow in case of breast cancer, resulting in increased foetal radiation exposure, but may be large enough to safely irradiate for brain or thyroid cancer. 


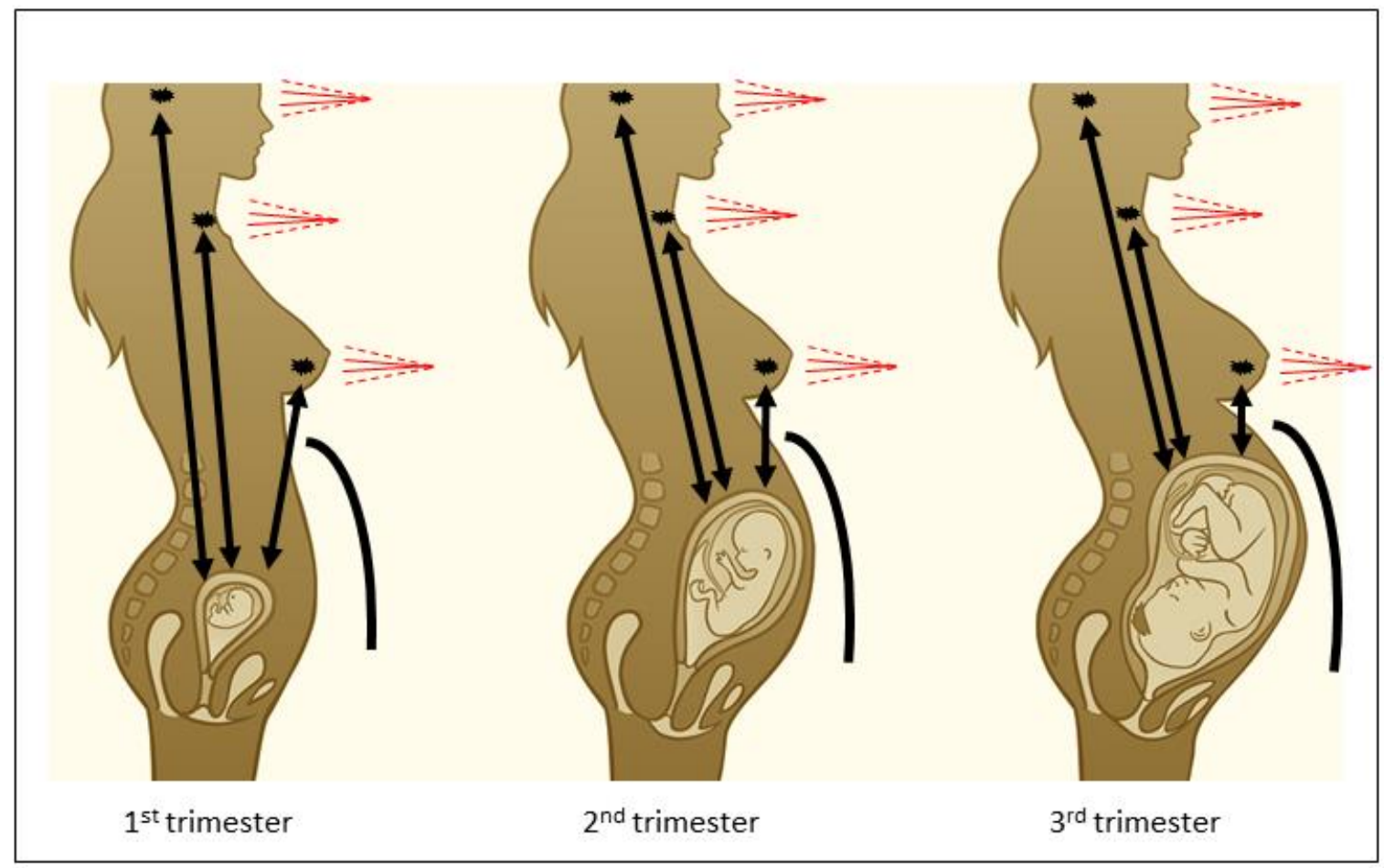

Figure 2. Foetal, neonatal and long-term risks of cancer treatment during pregnancy 

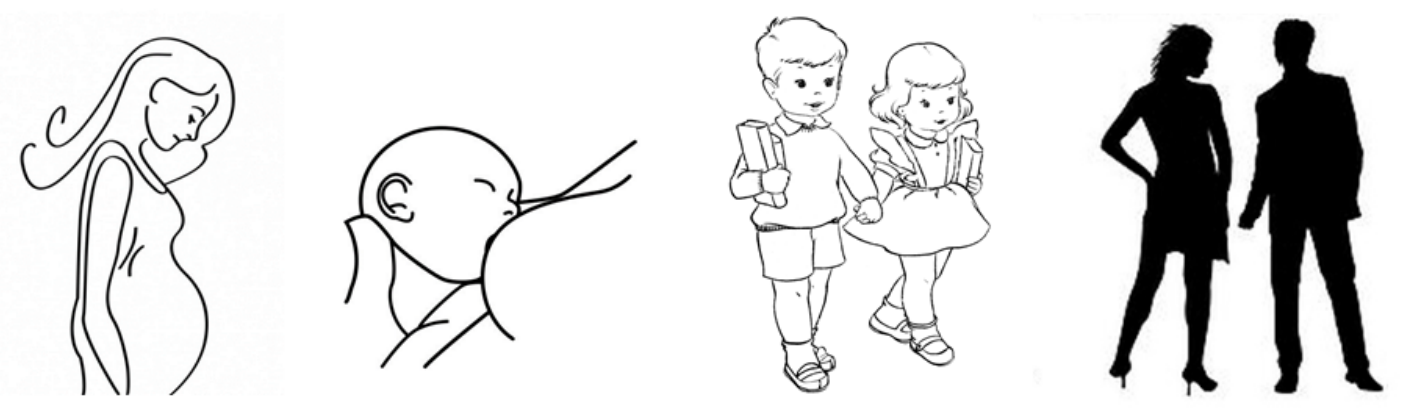

In utero

Birth

Child

Adult

Malformation

Preterm labour

PPROM

SGA

Prematurity

SGA

Haematological/

Cardiac problems
General health problems

Neurocognitive dysfunctions

Behaviour problems

Hearing impairment

Cardiac/ dental problems
Fertility problems

Cancer

Table 1

Stochastic and deterministic effects of irradiation

\begin{tabular}{|c|c|c|}
\hline Irradiation effects & Stochastic effects & $\begin{array}{c}\text { Deterministic effects } \\
\text { (= non-stochastic effects) }\end{array}$ \\
\hline Characteristics: & $\begin{array}{ll}- & \text { Occur by chance } \\
\text { - } & \text { No threshold point } \\
\text { - } & \text { Risk increases with dose } \\
\text { - } & \text { Severity unrelated to dose }\end{array}$ & $\begin{array}{ll}- & \text { Cause and effect relation-ship } \\
\text { - } & \text { Threshold below which the effect } \\
\text { does not occur } \\
\text { - } \quad \text { Above threshold increases severity } \\
\text { with the dose }\end{array}$ \\
\hline Examples: & $\begin{array}{ll}\text { - } & \text { Cancer development } \\
\text { - } & \text { Genetic effects }\end{array}$ & $\begin{array}{ll}\text { - } & \text { Congenital abnormalities } \\
\text { - } & \text { Lethality } \\
\text { - } & \text { Growth retardation } \\
\text { - } & \text { Metabolic and functional } \\
& \text { abnormalities }\end{array}$ \\
\hline
\end{tabular}

Table 2

Ongoing studies on cancer during pregnancy 


\begin{tabular}{|c|c|c|}
\hline Study coordinator & Studies on mothers & Studies on children \\
\hline \multirow[t]{5}{*}{$\begin{array}{l}\text { Frédéric Amant, Belgium } \\
\text { (International Network on } \\
\text { Cancer, Infertility and } \\
\text { Pregnancy (INCIP)) }\end{array}$} & $\begin{array}{l}\text { Registration of oncological and } \\
\text { obstetrical data of women } \\
\text { diagnosed with cancer during } \\
\text { pregnancy and of neonatal } \\
\text { outcome }\end{array}$ & $\begin{array}{l}\text { Evaluation of effects of cancer } \\
\text { and cancer treatment on fetal } \\
\text { health by investigating placental } \\
\text { physiology, DNA damage and } \\
\text { circulating markers in placental } \\
\text { and maternal and fetal (= } \\
\text { umbilical cord) blood }\end{array}$ \\
\hline & $\begin{array}{l}\text { Pharmacokinetics of } \\
\text { chemotherapy administered during } \\
\text { pregnancy }\end{array}$ & $\begin{array}{l}\text { Long-term follow-up of children } \\
\text { (until adulthood) after prenatal } \\
\text { exposure to cancer treatment, } \\
\text { with regard to general health, } \\
\text { cardiotoxicity, ototoxicity, dental } \\
\text { problems, neurocognitive } \\
\text { development and behaviour } \\
\text { problems }\end{array}$ \\
\hline & $\begin{array}{l}\text { Transfer of chemotherapeutic } \\
\text { agents through breastmilk }\end{array}$ & \multirow{3}{*}{$\begin{array}{l}\text { Magnetic resonance imaging } \\
\text { study of the brain to investigate } \\
\text { neurocognitive functioning after } \\
\text { prenatal exposure to cancer } \\
\text { treatment }\end{array}$} \\
\hline & $\begin{array}{l}\text { Evaluation of maternal and } \\
\text { paternal emotional wellbeing and } \\
\text { needs by means of a } \\
\text { questionnaire }\end{array}$ & \\
\hline & $\begin{array}{l}\text { Evaluation of Non-Invasive } \\
\text { Prenatal Testing (NIPT) for cancer } \\
\text { diagnosis by the detection of } \\
\text { genome representation profiles in } \\
\text { the maternal blood plasma }\end{array}$ & \\
\hline $\begin{array}{l}\text { Elyce Cardonick, USA } \\
\text { (International Cancer and } \\
\text { Pregnancy Registry) }\end{array}$ & $\begin{array}{l}\text { Registration of oncological and } \\
\text { obstetrical data of women } \\
\text { diagnosed with cancer during } \\
\text { pregnancy and of neonatal } \\
\text { outcome }\end{array}$ & $\begin{array}{l}\text { Evaluation of long-term effects of } \\
\text { prenatal exposure to cancer } \\
\text { treatment on general health, } \\
\text { neurocognitive development and } \\
\text { behaviour of the children }\end{array}$ \\
\hline $\begin{array}{l}\text { Irena Nulman, Canada } \\
\text { (Motherisk program } \\
\text { SickKids Toronto) }\end{array}$ & & $\begin{array}{l}\text { Evaluation of long-term effects of } \\
\text { maternal perinatal cancer and its } \\
\text { treatment on developing } \\
\text { foetuses and future paediatric } \\
\text { health }\end{array}$ \\
\hline Agustin Avilés, Mexico & & $\begin{array}{l}\text { Evaluation of long-term effects of } \\
\text { prenatal exposure to cancer } \\
\text { treatment on general health, } \\
\text { neurocognitive development and } \\
\text { cardiac functions }\end{array}$ \\
\hline $\begin{array}{l}\text { Sibylle Loibl, Germany } \\
\text { (German Breast Group) }\end{array}$ & $\begin{array}{l}\text { Registration of oncological and } \\
\text { obstetrical data of women } \\
\text { diagnosed with breast cancer } \\
\text { during pregnancy and of neonatal } \\
\text { outcome }\end{array}$ & \\
\hline
\end{tabular}




\section{POSTPRINT VERSION}

\section{References}

1. Lee YY, Roberts CL, Dobbins T, Stavrou E, Black K, Morris J, et al. Incidence and outcomes of pregnancy-associated cancer in Australia, 1994-2008: a population-based linkage study. BJOG. 2012;119(13):1572-82.

2. Parazzini F, Franchi M, Tavani A, Negri E, Peccatori FA. Frequency of Pregnancy Related Cancer: A Population Based Linkage Study in Lombardy, Italy. Int J Gynecol Cancer. 2017;27(3):6139.

3. Allaert SE, Carlier SP, Weyne LP, Vertommen DJ, Dutre PE, Desmet MB. First trimester anesthesia exposure and fetal outcome. A review. Acta Anaesthesiol Belg. 2007;58(2):119-23.

4. Mazze RI, Kallen B. Reproductive outcome after anesthesia and operation during pregnancy: a registry study of 5405 cases. Am J Obstet Gynecol. 1989;161(5):1178-85.

5. Cohen-Kerem R, Railton C, Oren D, Lishner M, Koren G. Pregnancy outcome following nonobstetric surgical intervention. Am J Surg. 2005;190(3):467-73.

6. Moran BJ, Yano H, Al Zahir N, Farquharson M. Conflicting priorities in surgical intervention for cancer in pregnancy. Lancet Oncol. 2007;8(6):536-44.

7. Evans SR, Sarani B, Bhanot P, Feldman E. Surgery in pregnancy. Curr Probl Surg. 2012;49(6):333-88.

8. Pearl J, Price R, Richardson W, Fanelli R, Society of American Gastrointestinal Endoscopic S. Guidelines for diagnosis, treatment, and use of laparoscopy for surgical problems during pregnancy.

Surg Endosc. 2011;25(11):3479-92.

9. Amant F, Van Calsteren K, Halaska MJ, Beijnen J, Lagae L, Hanssens M, et al. Gynecologic cancers in pregnancy: guidelines of an international consensus meeting. Int $\mathrm{J}$ Gynecol Cancer. 2009;19 Suppl 1:S1-12.

10. Kal HB, Struikmans H. Radiotherapy during pregnancy: fact and fiction. Lancet Oncol. 2005;6(5):328-33.

11. ICRP. Biological Effects after Prenatal Irradiation (Embryo and Fetus). ICRP Publication 90. Ann ICRP. 2003;33(1-2).

12. Otake M, Schull WJ. In utero exposure to A-bomb radiation and mental retardation; a reassessment. Br J Radiol. 1984;57(677):409-14.

13. Mazonakis M, Varveris H, Damilakis J, Theoharopoulos N, Gourtsoyiannis N. Radiation dose to conceptus resulting from tangential breast irradiation. Int J Radiat Oncol Biol Phys. 2003;55(2):38691.

14. Van Calsteren K, Verbesselt R, Beijnen J, Devlieger R, De Catte L, Chai DC, et al.

Transplacental transfer of anthracyclines, vinblastine, and 4-hydroxy-cyclophosphamide in a baboon model. Gynecol Oncol. 2010;119(3):594-600.

15. Van Calsteren K, Verbesselt R, Devlieger R, De Catte L, Chai DC, Van Bree R, et al.

Transplacental transfer of paclitaxel, docetaxel, carboplatin, and trastuzumab in a baboon model. Int $\mathrm{J}$ Gynecol Cancer. 2010;20(9):1456-64.

16. Amant F, Vandenbroucke T, Verheecke M, Fumagalli M, Halaska MJ, Boere I, et al. Pediatric Outcome after Maternal Cancer Diagnosed during Pregnancy. New Engl J Med. 2015;373(19):1824-

34.

17. Van Calsteren K, Heyns L, De Smet F, Van Eycken L, Gziri MM, Van Gemert W, et al. Cancer during pregnancy: an analysis of 215 patients emphasizing the obstetrical and the neonatal outcomes. J Clin Oncol. 2010;28(4):683-9.

18. Amant F, Van Calsteren K, Halaska MJ, Gziri MM, Hui W, Lagae L, et al. Long-term cognitive and cardiac outcomes after prenatal exposure to chemotherapy in children aged 18 months or older: an observational study. Lancet Oncol. 2012;13(3):256-64.

19. Murthy RK, Theriault RL, Barnett CM, Hodge S, Ramirez MM, Milbourne A, et al. Outcomes of children exposed in utero to chemotherapy for breast cancer. Breast Cancer Res. 2014;16(6):500.

20. Cardonick EH, Gringlas MB, Hunter K, Greenspan J. Development of children born to mothers with cancer during pregnancy: comparing in utero chemotherapy-exposed children with nonexposed controls. Am J Obstet Gynecol. 2015;212(5).

21. Cardonick E, lacobucci A. Use of chemotherapy during human pregnancy. Lancet Oncology. 2004;5(5):283-91.

22. Mendelsohn J. Personalizing oncology: perspectives and prospects. J Clin Oncol. 2013;31(15):1904-11.

23. Lambertini M, Peccatori FA, Azim HA, Jr. Targeted agents for cancer treatment during pregnancy. Cancer Treat Rev. 2015;41(4):301-9. 


\section{POSTPRINT VERSION}

24. Zagouri F, Sergentanis TN, Chrysikos D, Papadimitriou CA, Dimopoulos MA, Bartsch R. Trastuzumab administration during pregnancy: a systematic review and meta-analysis. Breast Cancer Res Treat. 2013;137(2):349-57.

25. Tewari K, Bonebrake RG, Asrat T, Shanberg AM. Ambiguous genitalia in infant exposed to tamoxifen in utero. Lancet. 1997;350(9072):183.

26. Berger JC, Clericuzio CL. Pierre Robin sequence associated with first trimester fetal tamoxifen exposure. Am J Med Genet A. 2008;146A(16):2141-4.

27. Cullins SL, Pridjian G, Sutherland CM. Goldenhar's syndrome associated with tamoxifen given to the mother during gestation. JAMA. 1994;271(24):1905-6.

28. Barthelmes L, Gateley CA. Tamoxifen and pregnancy. Breast. 2004;13(6):446-51.

29. Drew JH, Parkinson P, Walstab JE, Beischer NA. Incidences and types of malformations in newborn infants. Med J Aust. 1977;1(26):945-9.

30. Nicholson HO. Cytotoxic drugs in pregnancy. Review of reported cases. J Obstet Gynaecol Br Commonw. 1968;75(3):307-12.

31. Ebert U, Löffler H, Kirch W. Cytotoxic therapy and pregnancy. Pharmacol Ther. 1997;74(2):207-20.

32. Doll DC, Ringenberg QS, Yarbro JW. Management of cancer during pregnancy. Arch Intern Med. 1988;148(9):2058-64.

33. Aviles A, Neri N, Nambo MJ. Hematological malignancies and pregnancy: treat or no treat during first trimester. Int J Cancer. 2012;131(11):2678-83.

34. Han SN, Gziri MM, Van Calsteren K, Amant F. Is chemotherapy during the first trimester of pregnancy really safe? Int J Cancer. 2013;132(7):1728.

35. Aviles A, Neri N. Hematological malignancies and pregnancy: a final report of 84 children who received chemotherapy in utero. Clin Lymphoma. 2001;2(3):173-7.

36. Loibl S, Han SN, von Minckwitz G, Bontenbal M, Ring A, Giermek J, et al. Treatment of breast cancer during pregnancy: an observational study. Lancet Oncol. 2012;13(9):887-96.

37. Abdel-Hady e-S, Hemida RA, Gamal A, El-Zafarany M, Toson E, El-Bayoumi MA. Cancer during pregnancy: perinatal outcome after in utero exposure to chemotherapy. Arch Gynecol Obstet. 2012;286(2):283-6.

38. Cardonick E, Usmani A, Ghaffar S. Perinatal Outcomes of a Pregnancy Complicated by Cancer, Including Neonatal Follow-Up After in Utero Exposure to Chemotherapy Results of an International Registry. Am J Clin Oncol-Canc. 2010;33(3):221-8.

39. Pallotto EK, Kilbride HW. Perinatal outcome and later implications of intrauterine growth restriction. Clin Obstet Gynecol. 2006;49(2):257-69.

40. Sankaran S, Kyle PM. Aetiology and pathogenesis of IUGR. Best Pract Res Clin Obstet Gynaecol. 2009;23(6):765-77.

41. Wadhwa PD, Garite TJ, Porto M, Glynn L, Chicz-DeMet A, Dunkel-Schetter C, et al. Placental corticotropin-releasing hormone $(\mathrm{CRH})$, spontaneous preterm birth, and fetal growth restriction: a prospective investigation. Am J Obstet Gynecol. 2004;191(4):1063-9.

42. Maulik D, Frances Evans J, Ragolia L. Fetal growth restriction: pathogenic mechanisms. Clin Obstet Gynecol. 2006;49(2):219-27.

43. Lu D, Ludvigsson JF, Smedby KE, Fall K, Valdimarsdottir U, Cnattingius S, et al. Maternal Cancer During Pregnancy and Risks of Stillbirth and Infant Mortality. J Clin Oncol. 2017;35(14):15229.

44. Fischer D, Ahr A, Schaefer B, Veldman A, Schloesser R. Outcome of preterm and term neonates of mothers with malignant diseases diagnosed during pregnancy. $\mathrm{J}$ Matern Fetal Neonatal Med. 2006;19(2):101-3.

45. Garcia-Manero M, Royo MP, Espinos J, Pina L, Alcazar JL, Lopez G. Pregnancy associated breast cancer. Eur J Surg Oncol. 2009;35(2):215-8.

46. Cardonick E, Gilmandyar D, Somer RA. Maternal and Neonatal Outcomes of Dose-Dense Chemotherapy for Breast Cancer in Pregnancy. Obstet Gynecol. 2012;120(6):1267-72.

47. Wang ML, Dorer DJ, Fleming MP, Catlin EA. Clinical outcomes of near-term infants. Pediatrics. 2004;114(2):372-6.

48. Hahn KM, Johnson PH, Gordon N, Kuerer H, Middleton L, Ramirez M, et al. Treatment of pregnant breast cancer patients and outcomes of children exposed to chemotherapy in utero. Cancer. 2006;107(6):1219-26.

49. Chang A, Patel S. Treatment of acute myeloid leukemia during pregnancy. Ann Pharmacother. 2015;49(1):48-68. 


\section{POSTPRINT VERSION}

50. Cardonick E, Bhat A, Gilmandyar D, Somer R. Maternal and fetal outcomes of taxane chemotherapy in breast and ovarian cancer during pregnancy: case series and review of the literature. Ann Oncol. 2012;23(12):3016-23.

51. Broder H, Gottlieb RA, Lepor NE. Chemotherapy and cardiotoxicity. Rev Cardiovasc Med. 2008;9(2):75-83.

52. Mertens AC, Yasui Y, Neglia JP, Potter JD, Nesbit ME, Ruccione K, et al. Late mortality experience in five-year survivors of childhood and adolescent cancer: the Childhood Cancer Survivor Study. J Clin Oncol. 2001;19(13):3163-72.

53. Zucchi R, Danesi R. Cardiac toxicity of antineoplastic anthracyclines. Curr Med Chem Anticancer Agents. 2003;3(2):151-71.

54. Framarino-dei-Malatesta M, Perrone G, Giancotti A, Ventriglia F, Derme M, lannini I, et al. Epirubicin: a new entry in the list of fetal cardiotoxic drugs? Intrauterine death of one fetus in a twin pregnancy. Case report and review of literature. BMC Cancer. 2015;15:951.

55. Siedner S, Krüger M, Schroeter M, Metzler D, Roell W, Fleischmann BK, et al. Developmental changes in contractility and sarcomeric proteins from the early embryonic to the adult stage in the mouse heart. J Physiol. 2003;548(Pt 2):493-505.

56. Rudolph AM. Myocardial growth before and after birth: clinical implications. Acta Paediatr. 2000;89(2):129-33.

57. Aviles A, Neri N, Nambo MJ. Long-term evaluation of cardiac function in children who received anthracyclines during pregnancy. Ann Oncol. 2006;17(2):286-8.

58. Gziri MM, Amant F, Debieve F, Van Calsteren K, De Catte L, Mertens L. Effects of chemotherapy during pregnancy on the maternal and fetal heart. Prenat Diagn. 2012;32(7):614-9.

59. Clemens E, de Vries AC, Pluijm SF, Am Zehnhoff-Dinnesen A, Tissing WJ, Loonen JJ, et al. Determinants of ototoxicity in 451 platinum-treated Dutch survivors of childhood cancer: A DCOG lateeffects study. Eur J Cancer. 2016;69:77-85.

60. Caballero M, Mackers P, Reig O, Buxo E, Navarrete P, Blanch JL, et al. The Role of Audiometry prior to High-Dose Cisplatin in Patients with Head and Neck Cancer. Oncology. 2017. 61. Geijteman EC, Wensveen CW, Duvekot JJ, van Zuylen L. A child with severe hearing loss associated with maternal cisplatin treatment during pregnancy. Obstet Gynecol. 2014;124(2 Pt 2 Suppl 1):454-6.

62. Dens F, Boute P, Otten J, Vinckier F, Declerck D. Dental caries, gingival health, and oral hygiene of long term survivors of paediatric malignant diseases. Arch Dis Child. 1995;72(2):129-32.

63. Peretz B, Peretz T. The effect of chemotherapy in pregnant women on the teeth of offspring. Pediatr Dent. 2003;25(6):601-4.

64. Mennes M, Stiers P, Vandenbussche E, Vercruysse G, Uyttebroeck A, De Meyer G, et al. Attention and information processing in survivors of childhood acute lymphoblastic leukemia treated with chemotherapy only. Pediatr Blood Cancer. 2005;44(5):478-86.

65. Lofstad GE, Reinfjell T, Hestad K, Diseth TH. Cognitive outcome in children and adolescents treated for acute lymphoblastic leukaemia with chemotherapy only. Acta Paediatr. 2009;98(1):180-6. 66. Jackson GE. Chemo brain - a psychotropic drug phenomenon? Med Hypotheses. 2008;70(3):572-7.

67. Deprez S, Amant F, Smeets A, Peeters R, Leemans A, Van Hecke W, et al. Longitudinal assessment of chemotherapy-induced structural changes in cerebral white matter and its correlation with impaired cognitive functioning. J Clin Oncol. 2012;30(3):274-81.

68. Schuitema I, Deprez S, Van Hecke W, Daams M, Uyttebroeck A, Sunaert S, et al. Accelerated aging, decreased white matter integrity, and associated neuropsychological dysfunction 25 years after pediatric lymphoid malignancies. J Clin Oncol. 2013;31(27):3378-88.

69. Aluise CD, Sultana R, Tangpong J, Vore M, St Clair D, Moscow JA, et al. Chemo brain (chemo fog) as a potential side effect of doxorubicin administration: role of cytokine-induced, oxidative/nitrosative stress in cognitive dysfunction. Adv Exp Med Biol. 2010;678:147-56.

70. Achenbach TM, Rescorla LA. Manual for the ASEBA School-Age Forms \& Profiles. Burlington, VT: University of Vermont, Research Center for Children, Youth, \& Families; 2001.

71. Van den Bergh BRH, Mulder EJH, Mennes M, Glover V. Antenatal maternal anxiety and stress and the neurobehavioural development of the fetus and child: links and possible mechanisms. A review. Neurosci Biobehav R. 2005;29(2):237-58. 